\title{
The incidence of antibiotic resistance and other
} characteristics amongst Escherichia coli strains causing fatal infection in chickens: the utilization of these characteristics to study the epidemiology of the infection

\author{
By E. D. HELLER* AND H. WILLIAMS SMITH \\ Houghton Poultry Research Station, Houghton, Huntingdon PE17 2DA
}

(Received 2 April 1973)

\section{SUMMARY}

Of 173 epidemiologically unrelated strains of Escherichia coli isolated from the pericardial sac of chickens that had died from infection with these organisms in England in 1972, approximately 1 year after the introduction of legislation forbidding the routine use of feeds containing 'therapeutic' antibiotics, $83.8 \%$ were resistant to sulphonamides, $31 \cdot 2 \%$ to tetracyclines, $20 \cdot 8 \%$ to furazolidone, $18.5 \%$ to streptomycin, $2.9 \%$ to spectinomycin and $1.2 \%$ to ampicillin; none of the strains were resistant to chloramphenicol, neomycin, polymixin, trimethoprim or nalidixic acid. The sulphonamide resistance and possibly some of the resistance to other agents might have been the consequence of sulphonamides being exempted from the legislation. Much of the resistance, with the exception of that to furazolidone, was of the transferable type. Many strains possessed transfer factors in the absence of any known transferable characteristic. Colicine production was twice as common in the pathogenic strains as in a collection of strains isolated from the faeces of healthy chickens; about half of it was transferable.

By means of serology, antibiotic resistance and other markers, it was found that several different kinds of $E$. coli were usually incriminated in any one outbreak of $E$. coli infection in broiler chickens. Sometimes the same kinds of $E$. coli were found in outbreaks in consecutive crops of chickens on the same farm. New kinds, too, appeared to be brought in by replacement chickens.

\section{INTRODUCTION}

The routine use of tetracyclines as feed additives has given rise to large populations of tetracycline-resistant Escherichia coli in the alimentary tract of chickens (Smith \& Crabb, 1957). There is little doubt that it has also been responsible, in great part, for the high incidence of tetracycline resistance found amongst strains of $E$. coli pathogenic for poultry (Sojka \& Carnaghan, 1961). Following the report of the Swann Committee (Report, 1969), legislation was introduced in Britain in March 1971 prohibiting the use of 'therapeutic' antibiotics, except sulphonamides, as feed additives; their use for disease control on veterinary prescription, however,

* Present address: The Hebrew University of Jerusalem, Faculty of Agriculture, P.O Box 12, Rehovot, Israel. 
continued. It seemed worth while therefore to study the antibiotic resistance of strains of $E$. coli that had killed broiler chickens in Britain in 1972 to determine whether this legislation had had a more immediate effect and to form a 'base-line' for future assessments of its long-term effect. The results are presented here. The strains were also examined for antibiotic resistance, $R$ factors, non-transmissible but mobilizable resistance determinants, transfer factors, other transferable characters such as colicine (Col) and haemolysin (Hly) production and for lysogenicity. The information gained was then used to augment serological typing in studying the epidemiology of $E$. coli infection, because the value of the latter is limited by the fact that the majority of pathogenic poultry strains belong to one or other of only three serotypes, 02:K1, 01:K1 and 078:K80 (Sojka \& Carnaghan, 1961 ; Harry, 1964).

Escherichia coli strains

\section{MATERIALS AND METHODS}

These were obtained by culturing on MacConkey's agar the diseased pericardial sac of broiler chickens which, at autopsy, exhibited pathological lesions typical of $E$. coli infection. From the heavy $E$. coli growth that resulted, a single colony was picked, purified by replating and finally cultured on Dorset's egg medium. This was then maintained at $5^{\circ} \mathrm{C}$. until required.

\section{Escherichia coli strains from healthy chickens}

These were obtained from the faeces of chickens kept on different farms; they were not submitted for serotyping.

\section{Serological examination}

Glucose agar cultures were submitted to slide agglutination tests with 078:K80 and 02:K1 antisera. Those that agglutinated with the former antiserum were accepted as 078:K80. Those that agglutinated with the latter were made into a thick suspension with nutrient broth and autoclaved at $121^{\circ} \mathrm{C}$. for $30 \mathrm{~min}$. to destroy the $K$ antigens and expose the $O$ antigens. The suspensions were then centrifuged, resuspended in broth and submitted to slide agglutination tests employing 01:K1 and 02:K1 antisera suitably diluted to enable $\mathrm{O}$ suspensions of known 01:K1 and 02:K1 strains to be differentiated from each other.

\section{Antibiotic-sensitivity tests}

These were performed by the disk method described by Smith (1970) using an Oxoid Multodisk (1744E) composed of eight disks containing (i) streptomycin ( $\mathrm{Sm}$ ) $25 \mu$ g., (ii) ampicillin (A) $25 \mu$ g., (iii) oxytetracycline (T) $50 \mu$ g., (iv) chloramphenicol (Cm) $50 \mu \mathrm{g}$. , (v) neomycin (Neo) $30 \mu \mathrm{g} .$, (vi) nalidixic acid (Nal) $30 \mu \mathrm{g}$., (vii) furazolidone (F) $15 \mu \mathrm{g}$. and (viii) sulphonamides (Su) $300 \mu \mathrm{g}$., and three separate disks containing spectinomycin (Sp) $25 \mu \mathrm{g}$., polymixin (Pol) 300 units and sulphamethoxazole/tri-methoprim (SXT) $23 \cdot 75 \mu \mathrm{g}$. and 1.25 $\mu \mathrm{g}$. respectively. No difficulty was experienced in making readings; the zones of bacterial inhibition surrounding the disks were either wide, very narrow or absent. 


\section{Transfer of antibiotic resistance in vitro}

This was performed by the method described by Smith (1970), the prospective recipient strain being a nalidixic acid-resistant mutant $\left(n a l^{\mathrm{r}}\right)$ of $E$. coli $\mathrm{K} 12$ that was non-lactose fermenting $\left(l a c^{-}\right)$. The latter property provided an additional method of distinguishing the recipient strain from the prospective donor strains which, apart from being $n a l^{\mathrm{s}}$, were $l a c^{+}$. The concentrations of antibiotics employed in the selection media were as described above except that furazolidone was used at $10 \mu \mathrm{g} / \mathrm{ml}$. Strains that did not transmit their resistance were retested several times, with in addition a mutant of the $\mathrm{K} 12$ recipient strain resistant to several different colicines; this was done because most of the prospective donor strains examined were colicinogenic for the usual recipient strain and sometimes, in mixed culture, had a marked depressant effect on its growth rate.

\section{The identification of strains possessing only transfer factors or only resistance} determinants

For this we used the mobilization test of Anderson (1965), the actual technique employed being that described by Smith \& Linggood (1970). An E. coli K 12 strain possessing mobilizable determinants for streptomycin $\left(\mathrm{Sm}^{+}\right)$and sulphonamide $\left(\mathrm{Su}^{+}\right)$resistance was employed to identify strains possessing only transfer factors and $\mathrm{K} 12$ strains possessing transfer factor $\mathrm{F}$ or $\mathrm{I}$ were used to identify strains possessing only mobilizable determinants.

\section{Haemolysin and colicine production: their transferable nature}

Haemolysin production was detected by spot-inoculating broth cultures on plates of 'washed blood' agar (Smith \& Halls, 1967) and colicine production by spot-inoculation on plates of tryptose nutrient agar previously evenly spread with a broth culture of $E$. coli $\mathrm{K} 12$ suitably diluted to produce just confluent bacterial growth after incubation. All plates were incubated at $37^{\circ} \mathrm{C}$. for $24 \mathrm{hr}$. and read. The methods of Smith \& Gyles (1970) were employed to determine whether or not the haemolysin and colicine production of individual strains were transferable, the indicator for colicine production being the $\mathrm{nal}^{\mathrm{r}} \mathrm{lac}-\mathrm{K} 12$ strain.

\section{Colicine typing}

The technique employed was that described by Lewis (1968), using indicator strains received from Professor P. Fredericq.

\section{Identification of lysogenic strains}

A broth culture of the nalr lac- K 12 strain resistant to several different colicines was spread evenly over the surface of a plate of tryptose agar containing 0.02 $\mathrm{M}-\mathrm{CaCl}_{2}$ and $20 \mu \mathrm{g} . / \mathrm{ml}$. of sodium nalidixate. When dry, it was 'spot-inoculated' with young broth cultures of the strains of $E$. coli under test. The plates were incubated at $37^{\circ} \mathrm{C}$. and examined for evidence of phage action. 


\section{RESULTS}

Incidence of antibiotic resistance amongst strains of Escherichia coli isolated from diseased chickens

The antibiotic resistance found amongst 173 strains of $E$. coli isolated from the pericardial sac of chickens which had died in different outbreaks of clinical $E$. coli infection in England are illustrated in Table 1; over $60 \%$ of the strains belonged either to serotype $078: \mathrm{K} 80$ or $02: \mathrm{K} 1$. Only $13.3 \%$ of the strains were sensitive to all the 11 antibiotics against which they were tested. Sulphonamide resistance was by far the most common, followed by tetracycline, furazolidone and streptomycin resistance. Resistance to tetracyclines and streptomycin was found less frequently amongst the 02:K1 strains than amongst the others; the converse was true in the case of furazolidone resistance. With the exception of a few strains that were resistant to spectinomycin or ampicillin, all 173 were fully susceptible to the other seven antibiotics, including chloramphenicol, against which they were tested.

Sixteen different patterns of resistance were shown by the 173 strains. Apart from the large group that were resistant to sulphonamides only, none of the groups comprised $14 \%$ of the whole; most of them were much smaller. The resistance patterns were usually small, resistance to more than three antibiotics being uncommon.

The incidence of colicine and haemolysin production and lysogenicity amongst chicken strains of Escherichia coli

The results of examining the 173 pathogenic strains of Escherichia coli and 168 strains isolated from the faeces of healthy chickens from different farms for colicine production are summarized in Table 2. Most of the 078:K80 and 02:K1 strains and the other pathogenic strains produced colicines, the incidence being almost twice as high in these strains as in those isolated from the faeces of healthy chickens. Difficulty was experienced in identifying the actual colicines produced by the pathogenic strains as many strains produced more than one colicine. However, it was possible to divide all those that were identified into seven fairly well defined groups (1-7) according to the particular indicator strains which were susceptible to their colicinogenic activity. The percentage of the 173 epidemiologically unrelated pathogenic strains that fell into each group was : group 1, 28.5\%; group 2, $20.9 \%$; group $3,7 \cdot 6 \%$; group $4,13.9 \%$; group $5,5 \cdot 1 \%$; group $6,13.3 \%$; and group $7,10 \cdot 1 \%$.

Only one of the 173 pathogenic strains and one of the 168 strains isolated from the faeces of healthy chickens were haemolytic. Twelve (6.9\%) of the 173 pathogenic strains were lysogenic for $E$. coli $\mathrm{K} 12$. Three belonged to serotype 078:K80 and one to serotype 02:K1.

Antibiotic resistance, colicine and haemolysin production; their transferable nature in the chicken strains of Escherichia coli

The incidence of transferable antibiotic resistance, colicine and haemolysin production in the 173 pathogenic strains of $E$. coli and in the 168 other strains is 
Table 1. Incidence of antibiotic resistance amongst strains of Escherichia coli isolated from diseased chickens

\begin{tabular}{|c|c|c|c|c|}
\hline \multirow[b]{2}{*}{ Strains } & \multicolumn{4}{|c|}{ Serotypes } \\
\hline & $\mathrm{O} 78: \mathrm{K} 80$ & $\mathrm{O} 2: \mathrm{K} 1 *$ & $\begin{array}{l}\text { Other } \\
\text { serotypes }\end{array}$ & All \\
\hline No. examined ... & 43 & 63 & 67 & 173 \\
\hline $\begin{array}{l}\% \text { resistant to one or more drugs } \\
\% \text { resistant to }\end{array}$ & $83 \cdot 7$ & $88 \cdot 9$ & $85 \cdot 1$ & $86 \cdot 7$ \\
\hline Sulphonamides & $83 \cdot 7$ & $87 \cdot 3$ & $80 \cdot 6$ & $83 \cdot 8$ \\
\hline Tetracyclines & $37 \cdot 2$ & $14 \cdot 3$ & $43 \cdot 2$ & $31 \cdot 2$ \\
\hline Furazolidone & $18 \cdot 6$ & $28 \cdot 6$ & $14 \cdot 9$ & $20 \cdot 8$ \\
\hline Streptomycin & $28 \cdot 0$ & $3 \cdot 2$ & $23 \cdot 9$ & $18 \cdot 5$ \\
\hline Spectinomycin & $9 \cdot 3$ & $1 \cdot 6$ & 0 & $2 \cdot 9$ \\
\hline Ampicillin & 0 & $1 \cdot 6$ & 1.5 & $1 \cdot 2$ \\
\hline Neomycin & $\mathbf{0}$ & 0 & 0 & 0 \\
\hline Chloramphenicol & 0 & 0 & 0 & 0 \\
\hline Nalidixic acid & $\mathbf{0}$ & 0 & 0 & 0 \\
\hline Sulphamethoxazole/trimethoprim & 0 & 0 & 0 & 0 \\
\hline Polymixin & 0 & 0 & 0 & 0 \\
\hline$\%$ with resistance pattern $\dagger$ & & & & \\
\hline $\mathrm{Su}$ & $30 \cdot 0$ & $44 \cdot 5$ & $35 \cdot 9$ & $\mathbf{3 7} \cdot 6$ \\
\hline $\mathrm{Su} \mathbf{T}$ & $18 \cdot 6$ & $9 \cdot 5$ & $15 \cdot 0$ & $13 \cdot 9$ \\
\hline $\mathrm{Su} \mathrm{F}$ & $2 \cdot 3$ & $22 \cdot 2$ & $1 \cdot 5$ & $9 \cdot 3$ \\
\hline $\mathrm{Sm} \mathrm{Su} \mathrm{T}$ & $4 \cdot 7$ & $1 \cdot 6$ & $15 \cdot 0$ & $7 \cdot 5$ \\
\hline Sm Su T F & $7 \cdot 0$ & 0 & $6 \cdot 0$ & $4 \cdot 1$ \\
\hline Su T F & $4 \cdot 7$ & $3 \cdot 2$ & $4 \cdot 5$ & $4 \cdot 1$ \\
\hline $\mathrm{Sm} \mathrm{Su}$ & $4 \cdot 7$ & $3 \cdot 2$ & 0 & $2 \cdot 3$ \\
\hline $\mathrm{Sm} S u \mathrm{Sp} F$ & $2 \cdot 3$ & $1 \cdot 6$ & 0 & $1 \cdot 2$ \\
\hline $\mathrm{Sm} \mathrm{Su} \mathrm{F}$ & $2 \cdot 3$ & 0 & $1 \cdot 5$ & $1 \cdot 2$ \\
\hline $\mathrm{Sm} \mathrm{Su} \mathrm{Sp}$ & $4 \cdot 7$ & 0 & 0 & $1 \cdot 2$ \\
\hline $\mathbf{F}$ & 0 & $1 \cdot 6$ & 1.5 & $1 \cdot 2$ \\
\hline A Sm Su T & 0 & 0 & $1 \cdot 5$ & $0 \cdot 6$ \\
\hline Sm Su T Sp & $2 \cdot 3$ & 0 & 0 & $0 \cdot 6$ \\
\hline $\mathrm{A} \mathrm{Su}$ & 0 & $1 \cdot 6$ & 0 & $0 \cdot 6$ \\
\hline $\mathrm{Sm}$ & 0 & 0 & 1.5 & $0 \cdot 6$ \\
\hline$T$ & 0 & 0 & 1.5 & 0.6 \\
\hline
\end{tabular}

* Includes two 01:K1 strains.

$\dagger \mathrm{A}=$ ampicillin; $\mathrm{F}=$ furazolidone; $\mathrm{Sm}=$ streptomycin, $\mathrm{Sp}=$ spectinomycin; $\mathrm{Su}=$ sulphonamides; $\mathbf{T}=$ tetracyclines.

illustrated in Table 3. So is the incidence of transfer factors in those strains not shown to possess transferable characters. Most of the spectinomycin and ampicillin resistance and about half the tetracycline and streptomycin resistance was transferred to $E$. coli $\mathrm{K} 12$, the incidence of transferable streptomycin resistance being higher in the pathogenic group than in the other group. The incidence of transferable tetracycline resistance was lowest in the untyped pathogenic strains. Less than $20 \%$ of the sulphonamide resistance and none of the furazolidone resistance was transferable. Colicine production was transferable in about half the strains possessing this character, the incidence of transferability being similar in both groups. The incidence of transfer factors in strains not possessing known transferable characters was highest in the 078:K80 strains and in the untyped pathogenic strains. There 
Table 2. The incidence of colicine production amongst strains of Escherichia coli isolated from chickens

\begin{tabular}{|c|c|c|c|c|c|}
\hline & \multicolumn{5}{|c|}{ Source of strains } \\
\hline & \multicolumn{4}{|c|}{ Diseased chickens } & \multirow{2}{*}{$\begin{array}{c}\text { Healthy chickens } \\
\text { Untyped } \\
\text { serologically }\end{array}$} \\
\hline & O78: K80 & $\mathrm{O} 2: \mathrm{K} 1^{*}$ & $\begin{array}{l}\text { Other } \\
\text { serotypes }\end{array}$ & Total & \\
\hline No. examined & 43 & 63 & 67 & 173 & 168 \\
\hline No. colicine-positive & 38 & 59 & 55 & 152 & 78 \\
\hline Colicine-positive (\%) & $88 \cdot 4$ & $93 \cdot 6$ & $82 \cdot 1$ & $87 \cdot 8$ & $46 \cdot 4$ \\
\hline
\end{tabular}

Table 3. The incidence of transferable antibiotic resistance, colicine and haemolysin production and transfer factors in chicken strains of Escherichia coli

\begin{tabular}{|c|c|c|c|c|c|}
\hline \multirow[b]{3}{*}{ Characteristic* } & \multicolumn{5}{|c|}{ Source of strains } \\
\hline & \multicolumn{4}{|c|}{ Diseased chickens } & \multirow{2}{*}{$\begin{array}{c}\text { Healthy chickens } \\
\text { Untyped } \\
\text { serologically }\end{array}$} \\
\hline & O78: K80 & $\mathrm{O} 2: \mathrm{K} 1$ & $\begin{array}{c}\text { Other } \\
\text { serotypes }\end{array}$ & Total & \\
\hline $\mathrm{Sm}$ & $\begin{array}{c}9 / 12 \dagger \\
(75 \cdot 0)\end{array}$ & $\begin{array}{l}0 / 2 \\
(0)\end{array}$ & $\begin{array}{r}7 / 17 \\
(41 \cdot 2)\end{array}$ & $\begin{array}{l}16 / 31 \\
(51 \cdot 6)\end{array}$ & $\begin{array}{r}7 / 27 \\
(25 \cdot 9)\end{array}$ \\
\hline $\mathrm{Su}$ & $\begin{array}{l}10 / 36 \\
(27 \cdot 8)\end{array}$ & $\begin{array}{l}3 / 56 \\
(5 \cdot 4)\end{array}$ & $\begin{array}{l}11 / 53 \\
(20 \cdot 8)\end{array}$ & $\begin{array}{l}24 / 145 \\
(16 \cdot 5)\end{array}$ & $\begin{array}{l}19 / 102 \\
(18 \cdot 6)\end{array}$ \\
\hline $\mathbf{T}$ & $\begin{array}{l}10 / 14 \\
(71 \cdot 4)\end{array}$ & $\begin{array}{c}8 / 9 \\
(88 \cdot 9)\end{array}$ & $\begin{array}{r}7 / 28 \\
(25 \cdot 0)\end{array}$ & $\begin{array}{l}25 / 51 \\
(49 \cdot 0)\end{array}$ & $\begin{array}{l}28 / 52 \\
(53 \cdot 8)\end{array}$ \\
\hline $\mathrm{Sp}$ & $\begin{array}{c}3 / 4 \\
(75 \cdot 0)\end{array}$ & $\begin{array}{c}1 / 1 \\
(100)\end{array}$ & $0 / 0$ & $\begin{array}{c}4 / 5 \\
(80)\end{array}$ & $\begin{array}{l}0 / 3 \\
(0)\end{array}$ \\
\hline $\mathbf{A}$ & $0 / 0$ & $\begin{array}{c}1 / 1 \\
(100)\end{array}$ & $\begin{array}{c}1 / 1 \\
(100)\end{array}$ & $\begin{array}{c}2 / 2 \\
(100)\end{array}$ & $\begin{array}{c}3 / 3 \\
(100)\end{array}$ \\
\hline $\mathbf{F}$ & $\begin{array}{l}0 / 8 \\
(0)\end{array}$ & $\begin{array}{l}0 / 18 \\
(0)\end{array}$ & $\begin{array}{l}0 / 10 \\
(0)\end{array}$ & $\begin{array}{l}0 / 36 \\
(0)\end{array}$ & $\begin{array}{l}0 / 8 \\
(0)\end{array}$ \\
\hline Col & $\begin{array}{l}22 / 38 \\
(57 \cdot 8)\end{array}$ & $\begin{array}{l}30 / 59 \\
(50 \cdot 8)\end{array}$ & $\begin{array}{l}30 / 55 \\
(54 \cdot 5)\end{array}$ & $\begin{array}{l}82 / 152 \\
(53 \cdot 9)\end{array}$ & $\begin{array}{l}41 / 78 \\
(42 \cdot 6)\end{array}$ \\
\hline Hly & $0 / 0$ & $0 / 0$ & $\begin{array}{l}0 / 1 \\
(0)\end{array}$ & $\begin{array}{l}0 / 1 \\
(0)\end{array}$ & $\begin{array}{l}0 / 1 \\
(0)\end{array}$ \\
\hline Tra $\ddagger$ only & $\begin{array}{r}6 / 12 \\
(50 \cdot 0)\end{array}$ & $\begin{array}{r}4 / 21 \\
(19 \cdot 1)\end{array}$ & $\begin{array}{l}15 / 25 \\
(60 \cdot 0)\end{array}$ & $\begin{array}{l}25 / 58 \\
(43 \cdot 1)\end{array}$ & $\begin{array}{l}16 / 90 \\
(17 \cdot 8)\end{array}$ \\
\hline
\end{tabular}

The figures in parentheses are percentages.

* Sm, Su, T, Sp, A, F, Col, Hly and Tra are genetic determinants for streptomycin, sulphonamides, tetracyclines, spectinomycin, ampicillin and furazolidone resistance, colicine and haemolysin production and transfer factor.

$\dagger$ No. of strains in which it was transferable/no. of strains tested.

$\ddagger$ Presence of transfer factor in absence of any characters shown to be transmissible. 
were several examples of strains possessing transfer factors yet being unable to transfer their own tetracycline, streptomycin and sulphonamide resistance and their colicine production. By means of transfer factors $\mathrm{F}$ and $\mathrm{I}$, it was possible to mobilize the non-transfering resistance possessed by three strains.

The isolation of different types of Escherichia coli from outbreaks of Escherichia coli infection in broiler chickens

The results of examining strains of $E$. coli isolated from the hearts of chickens that had died from $E$. coli infection on three broiler farms are summarized in Tables 4-6; the chickens belonged to one or other of three successive crops. Table 6 also shows the results for strains isolated from the infected yolk sacs of 20 oneday-old chicks belonging to the second crop of farm $\mathrm{C}$ which had died immediately before they were taken to the farm. None of the chickens on the farms had been given antibiotics or any other agents active against $E$. coli. Each farm consisted of 10-17 broiler houses sited close together and, although one particular kind of $E$. coli was sometimes isolated more commonly from dead chickens from one house than from another, this occurrence did not seem sufficiently common to justify considering each house as a separate unit.

Strains belonging to serotype 02:K1, 078: K80 and to other, unidentified, serotypes were present amongst those isolated from chickens from all three crops on all three farms. According to antibiotic sensitivity, production of colicine and haemolysin and lysogenicity, these could be further classified into a comparatively large number of different kinds, many of which were incriminated in the deaths that occurred in each crop, e.g. the number of kinds isolated from the dead chickens in the first crops examined from farms $\mathrm{A}, \mathrm{B}$ and $\mathrm{C}$ were 10,9 and 4 respectively. It was not unusual for the same kinds of $E$. coli to be isolated from some of the chickens in all three crops on each farm. A notable example of this was the finding of an antibiotic-sensitive, colicine-producing strain of 078:K80 E. coli, to be the most common kind causing disease in all three crops on farm B. A kind of $E$. coli 078:K80, sulphonamide and tetracycline-resistant, colicine-producing, and also lysogenic, was responsible for most of the deaths in the first and second crop on farm C; it was also isolated from dead chickens of the third crop but most of the deaths in this crop were caused by an 02:K1 kind of $E$. coli. These two kinds of $E$. coli 078:K80 were not commonly found amongst the epidemiologically unrelated strains illustrated in Table 1. Several kinds of $E$. coli isolated from chickens in the second and third crops of farm $\mathrm{C}$ resembled some of those that had been isolated from the infected yolk sacs of the dead chicks that would have formed part of the second crop. The colicine produced by the $02: \mathrm{K} 1$ strain isolated from one of these chicks was the same as that produced by some of the $02: \mathrm{K} 1$ strains that were isolated later from dead chickens of this crop and of the third crop.

A total of 198 strains of $E$. coli isolated from the hearts of chickens, one per chicken, that had died from $E$. coli infection on 36 other farms, 4-10 (average 5.5) per farm, were also examined. The number of kinds of $E$. coli amongst the strains from each farm varied from 1 to 6 (average 2.5); those from each of ten of the farms were of the same kind. 
Table 4. The different kinds of Escherichia coli isolated from 236 dead chickens in successive broiler crops on farm $A$

\begin{tabular}{|c|c|c|c|}
\hline \multirow[b]{2}{*}{ Kind of $E$. coli $^{*}$} & \multicolumn{3}{|c|}{$\begin{array}{l}\text { No. of strains isolated } \\
\text { from dead chickens in } \\
\text { crop no. }\end{array}$} \\
\hline & 1 & 2 & 3 \\
\hline \multicolumn{4}{|l|}{$\mathrm{O} 2: \mathrm{K} 1$} \\
\hline $\mathrm{Su} \mathrm{Col}$ & 2 & 14 & 4 \\
\hline $\mathrm{Su}$ T Col & 0 & $\mathbf{0}$ & 4 \\
\hline $\mathrm{Su}$ F Col & 0 & 1 & 0 \\
\hline \multicolumn{4}{|l|}{ O78:K80 } \\
\hline Col & 22 & 4 & 9 \\
\hline S Su Sp Col & 34 & 4 & 0 \\
\hline \multicolumn{4}{|l|}{ Untyped $\dagger$} \\
\hline Col & 4 & 8 & 0 \\
\hline $\mathrm{Su}$ & 6 & 1 & 2 \\
\hline $\mathrm{Su} \mathrm{Col}$ & 15 & 39 & 0 \\
\hline Su T & 0 & 7 & 0 \\
\hline $\mathrm{Su}$ T Col & 8 & 7 & 8 \\
\hline Su T F Col & 1 & $\mathbf{5}$ & 0 \\
\hline Su F Col & 0 & $\mathbf{5}$ & 0 \\
\hline S Su T Col & 3 & 5 & 10 \\
\hline S Su T F Col & 1 & 3 & 0 \\
\hline All kinds & 96 & 103 & 37 \\
\hline
\end{tabular}

One strain from the heart of each dead chicken was examined.

* S, Sp, Su, T and $\mathrm{F}=$ resistant to streptomycin, spectinomycin, sulphonamides, tetracycline and furazolidone. $\mathrm{Col}=$ colicine-producing.

† Neither 078:K80, O1:K1 or O2:K1.

\section{DISCUSSION}

Despite the introduction of legislation, some 12 months previously, banning the use of 'therapeutic' agents as feed additives, the incidence of tetracycline and furazolidone resistance found in the present survey amongst strains of Escherichia coli pathogenic for poultry was still 31.2 and $20.8 \%$ respectively. It will be of interest to see whether or not these figures will decrease significantly with time, now that the use of these two agents in feeds has been restricted. The high incidence of resistance to sulphonamides, $83.8 \%$, was not unexpected because it is still permissible to feed diets containing these agents continuously to poultry to prevent coccidiosis. It is doubtful whether the streptomycin resistance possessed by $18.5 \%$ of the pathogenic strains can be attributed to the selection pressure of streptomycin itself because this antibiotic is rarely given to poultry. It may well be a reflexion of the use of sulphonamides, as the genetic determinants for resistance to streptomycin and sulphonamides are often located on the same plasmid. It is possible, too, that the use of sulphonamides may be playing a part in maintaining the high incidence of tetracycline resistance because practically all the tetracycline-resistant $E$. coli examined were also resistant to these agents. If sulphonamides are acting in this manner it calls into question the advisability of 
Table 5. The different kinds of Escherichia coli isolated from 274 dead chickens in successive crops on farm $B$

\begin{tabular}{|c|c|c|c|}
\hline \multirow[b]{2}{*}{ Kind of E. coli* } & \multicolumn{3}{|c|}{$\begin{array}{l}\text { No. of strains isolated } \\
\text { from dead chickens in } \\
\text { crop no. }\end{array}$} \\
\hline & 1 & 2 & $\mathbf{3}$ \\
\hline \multicolumn{4}{|l|}{$\mathrm{O} 2: \mathrm{K} 1$} \\
\hline $\mathrm{Su}$ & 0 & 0 & 7 \\
\hline $\mathrm{Su} \mathrm{Col}$ & 1 & 30 & 4 \\
\hline Su T Col & 0 & 3 & 0 \\
\hline \multicolumn{4}{|l|}{ O78:K80 } \\
\hline $\mathrm{Su}$ & 1 & 0 & $\mathbf{0}$ \\
\hline Col & 38 & 42 & 24 \\
\hline S Su T Col & $\mathbf{0}$ & 2 & $\mathbf{1}$ \\
\hline \multicolumn{4}{|l|}{ Untyped } \\
\hline Col & 1 & 0 & $\mathbf{0}$ \\
\hline Su Col & 7 & 15 & 2 \\
\hline $\mathbf{T}$ & 1 & 0 & 0 \\
\hline Su T Col & 2 & 6 & 3 \\
\hline Su T F Col & 0 & 3 & 0 \\
\hline $\mathrm{S} \mathrm{Su} \mathrm{T}$ & 0 & 4 & 0 \\
\hline Su F Col & 0 & 5 & $\mathbf{0}$ \\
\hline S Su T Col & 2 & 29 & 5 \\
\hline S Su T F Col & 19 & 0 & $\mathbf{0}$ \\
\hline Su Col Hly & 0 & 15 & 2 \\
\hline All kinds & 72 & 154 & 48 \\
\hline
\end{tabular}

* Hly = haemolytic. For other details see Table 4.

Table 6. The different kinds of Escherichia coli isolated from 200 dead chickens in successive broiler crops on farm $C$

No. of strains of this kind isolated from dead chickens in crop no.

Kind of $E$. coli*

$\overbrace{12 \mathrm{~A} \dagger}^{2 \mathrm{~B} \quad 3}$

$\mathrm{O} 2: \mathrm{K} 1$

Su Col

Su F Col

$\begin{array}{rrrr}0 & 1 & 2 & 46 \\ 3 & 0 & 0 & 0 \\ 73 & 0 & 10 & 12\end{array}$

O78:K80 Su T Col Lys

Untyped

Unclassifiable

Col

$\mathrm{Su}$

$\mathrm{Su} \mathrm{Col}$

Su T Col

Su F Col

S Su T Col

$\begin{array}{rrrr}0 & 1 & 2 & 1 \\ 0 & 3 & 0 & 9 \\ 1 & 4 & 1 & 1 \\ 0 & 7 & 1 & 7 \\ 0 & 1 & 2 & 6 \\ 2 & 3 & 0 & 0 \\ 0 & 0 & 0 & 1 \\ 79 & 20 & 18 & 83\end{array}$

All kinds

79

20

18

83

* Lys = lysogenic for $E$. coli $\mathrm{K} 12$. For other details see Table 4.

$\dagger$ Strains from infected yolk sacs of 1-day-old chicks of crop no. 2; they had died immediately before being brought to farm $\mathrm{C}$. 
their continued use as feed additives unless, of course, it can be shown, as alleged, that they are essential in coccidiosis control. The complete absence of strains resistant to neomycin, chloramphenicol, nalidixic acid, trimethoprim and polymixin is in keeping with the fact that these agents are seldom, if ever, administered to poultry.

The failure to transfer furazolidone resistance from all 44 strains of $E$. coli examined confirms the observations of Smith (1966), from which it appears that transferable furazolidone resistance in $E$. coli, in contrast to resistance to most other antibiotics, must be uncommon. The high incidence of pathogenic strains, other than those of serotype $02: \mathrm{K} 1$, possessing transfer factors and no identifiable transferable characteristics suggests that these strains, in fact, may possess transferable characteristics that, in some way, are associated with pathogenicity, as was found in the case of strains enteropathogenic for pigs (Smith \& Linggood, 1970). It is noteworthy, too, that colicinogenicity, shown to be transferable in over $50 \%$ of the strains examined, was twice as common in the pathogenic strains as in those isolated from the faeces of healthy chickens.

The results of classifying strains from different outbreaks according to serology, antibiotic resistance pattern, colicine and haemolysin production and lysogenicity have served to augment those previously made by Harry (1964), Harry \& Hemsley (1965) and Hemsley \& Harry (1965) using serological methods only. They show, for example, that several different strains may be involved in any outbreak. This finding stresses the desirability of performing antibiotic sensitivity tests on a number of strains before selecting an antibiotic with which to treat a particular outbreak. It suggests, too, that vaccines giving coverage against a wide variety of strains would be essential if immunological procedures were to be successful in preventing such outbreaks. It is also apparent from the examination of strains from farms A, B and C that (1) pathogenic strains may persist in broiler houses and thus give rise to outbreaks of clinical infection in consecutive crops of birds and (2) new pathogenic strains can be brought in by the replacement chicks themselves.

We are grateful to Mr Philip Green for his capable technical help. Our thanks are also due to Professor P. Fredericq, Dr R. F. Gordon, Dr E. G. Harry, Mrs Anne Millington and $\mathrm{Mr}$ W. J. Sojka for assistance in various ways.

\section{REFERENCES}

Anderson, E. S. (1965). A rapid screening test for transfer factor in drug sensitive Enterobacteriaceae. Nature, London 208, 1016-17.

HARRY, E. G. (1964). A study of 119 outbreaks of coli septicaemia in broiler flocks. Veterinary Record 76, 443-8.

HaRRY, E. G. \& Hemsley, L. A. (1965). The relationship between environmental contamination with septicaemia strains of Escherichia coli and their incidence in chickens. Veterinary Record 77, 241-5.

Hemsley, L. A. \& Harry, E. G. (1965). Coliform pericarditis (colisepticaemia) in broiler chickens: a three year study on one farm. Veterinary Record 77, 103-7.

LEwIs, M. J. (1968). Transferable drug resistance and other transferable agents in strains of Escherichia coli from two human populations. Lancet i, 1389-93.

REPORT (1969). Report of the Joint Committee on the Use of Antibiotics in Animal Husbandry and Veterinary Medicine. London: H.M.S.O. 
SmItH, H. W. (1966). The incidence of infective drug resistance in strains of Escherichia coli isolated from diseased human beings and domestic animals. Journal of Hygiene 64, 465-74.

SмrтH, H. W. (1970). The transfer of antibiotic resistance between strains of enterobacteria in chickens, calves and pigs. Journal of Medical Microbiology 3, 165-80.

Smith, H. W. \& CraBb, W. E. (1957). The effect of the continuous administration of diet containing low levels of tetracycline on the incidence of drug resistant Bacterium coli in the faeces of pigs and chickens: the sensitivity of the Bact. coli to other chemotherapeutic agents. Veterinary Record 69, 24-30.

Smith, H. W. \& Gyles, C. L. (1970). The relationship between different transmissible plasmids introduced by $\mathrm{F}$ into the same strain of Escherichia coli $\mathrm{K} 12$. Journal of General Microbiology 62, 277-85.

Sмrтн, H. W. \& HaLLS, S. (1967). The transmissible nature of the genetic factor of Escherichia coli that controls haemolysin production. Journal of General Microbiology 47, 153-61.

Smith, H. W. \& Linggood, M. A. (1970). Transfer factors in Escherichia coli with particular regard to their incidence in enteropathogenic strains. Journal of General Microbiology 62, 287-99.

Sojka, W. J. \& Carnaghan, R. B. A. (1961). Escherichia coli infection in poultry. Research in Veterinary Science 2, 340-52. 